www.periodicos.unimontes.br/index.php/caminhosdahistoria

\title{
Resenha
}

Resenha do livro: GUEDES, Roberto. Egressos do cativeiro: trabalho, família, aliança e mobilidade social: (Porto Feliz, São Paulo, 1798-1850). Rio de Janeiro: Mauad X; FAPERJ, 2008. 401p.

\section{OS SIGNIFICADOS DA MOBILIDADE SOCIAL PARA FORROS E SEUS DESCENDENTES}

\author{
Iara de Oliveira Maia ${ }^{1}$
}

Analisar as vivências de libertos e seus descendentes através de um conjunto variado de fontes, e conseguir reconstituir trajetórias de famílias com ascendência escrava numa área de produção agrícola para o mercado interno - e, por isso mesmo, representativa de regiões agrárias do Brasil escravista do século XIX - foi o que propôs Roberto Guedes em seu livro.

Este trabalho é resultado de sua tese de doutorado defendida na UFRJ em 2005, e tem como recorte espacial a vila de Porto Feliz, na capitania/província de São Paulo, no período de fins do século XVIII e início do XIX (especificamente a primeira metade do século XIX), e como tema central a mobilidade social. $\mathrm{O}$ autor procurou analisar as estratégias de ascensão social empreendidas por libertos e seus descendentes, tais como o trabalho, a estabilidade familiar, a inserção em redes de socialização, dentre outros. Para isso, utilizou como método de abordagem o proposto pela micro-história, realizando um trabalho intenso com diversos tipos de fontes, onde utilizou a técnica do cruzamento onomástico: listas nominativas de habitantes, registros paroquiais de batismo, casamento e óbito, inventários post-mortem, testamentos e prestação de contas de testamentos, notas cartoriais, licenças expedidas pela Câmara Municipal, processos crimes, etc. Assim, foi possível ao autor acompanhar por mais de quatro gerações as trajetórias de libertos e descendentes como, por exemplo, o caso da família Rocha.

Além do trabalho com as fontes, vale ressaltar o cuidado do autor em dialogar com a historiografia no decorrer do livro - como os trabalhos e pressupostos da historiadora Hebe

\footnotetext{
1 Mestre, licenciada e bacharel em História pela Universidade Federal de Ouro Preto (UFOP). Email: iaramaia_ufop@yahoo.com.br. ORCID: https://orcid.org/0000-0002-4762-4836.
} 
Mattos (1995; 2000), referência nos debates propostos - importante não só para situar sua abordagem, apontar questões que está de acordo ou não, como também para comparar os dados levantados para Porto Feliz com os de outras localidades. Algumas questões importantes para a compreensão de seu livro são o fato do autor entender a sociedade de Porto Feliz como uma sociedade com traços de Antigo Regime e a escravidão como sendo parte integrante dela, ou seja, uma sociedade com traços estamentais e escravista, onde a mobilidade social é entendida não só pela mudança de posição na hierarquia social estamental, mas também pelo viés intragrupal e ainda "não deve ser confundida apenas com enriquecimento" (Guedes, 2008, p. 87). Antes, o mais importante era a manutenção e/ou a redefinição do lugar ocupado na hierarquia social, para o que a riqueza podia colaborar ou não. Desta maneira, Guedes procurou entender como se deu a trajetória de forros e descendentes, apresentando seu livro dividido em cinco capítulos, que se destacam pela riqueza de detalhes não só na forma de escrever, bem como através de quadros, gráficos, diagramas, que nos permitem perceber de forma ampla e precisa a vila de Porto Feliz e sua população.

Primeiramente, é apresentada a paisagem agrária da pequena Porto Feliz, que até 1797 era a freguesia de Araritaguaba, quando foi elevada a vila. Durante todo o século XVIII, este lugarejo foi fundamental na rota fluvial das monções quando se descobriu minas de ouro em Coxipó-Mirim e Cuiabá. Já nos primeiros anos do século XIX, o comércio das monções teve sua importância diminuída devido ao surgimento de outras rotas, o que coincidiu com o desenvolvimento da economia canavieira no oeste paulista, desenvolvimento que Porto Feliz acompanhou, se inserindo entre os municípios situados no "Quadrilátero do Açúcar", área compreendida entre Sorocaba, Piracicaba, Mogi-Guaçú e Jundiaí.

Guedes mostra como o cultivo da cana-de-açúcar, voltado para o mercado externo à vila, estimulou o desenvolvimento de Porto Feliz, possibilitando o crescimento do "miolo urbano" com construção de algumas casas, instalação de vendas; influenciou também o aumento da população, principalmente da população escrava em função do tráfico de cativos para trabalhar nas lavouras; estimulou o mercado de animais e a criação de gado para alimentação e para moverem os engenhos, e também a produção de alimentos como milho, feijão, arroz, entre outros, destinados ao consumo próprio e comercializados na vila. Inicialmente, foram os pequenos escravistas que participaram plenamente da atividade açucareira, mas a partir de 1820-1824 os grandes produtores aumentaram sua participação e intensificaram a concentração da propriedade escrava. Para a montagem de um engenho era preciso cabedais, e o crédito foi fundamental para o financiamento, assim como o fato dos 
senhores de engenho se dedicarem a outras atividades como negócio de fazendas secas, lavouras, o comércio das monções, etc.

Ao verificar em seus dados levantados para Porto Feliz o exercício de outras atividades pelos principais da terra, Roberto Guedes estabelece um intenso diálogo com a historiografia, tendo o 'trabalho' como questão importante. Assim, a partir do conceito de trabalho de Caio Prado Jr. no passado colonial/imperial no Brasil e da análise de outros estudos que seguem a mesma perspectiva, o autor matiza a idéia de que o defeito mecânico e a escravidão inviabilizaram o trabalho livre não só no sentido de ocupação de espaços nas esferas produtivas, mas também no de imputar estigma social a trabalhadores, em especial a forros e descendentes. Tendo como base estudos como os do historiador João Fragoso, comparando os dados levantados para outras localidades com Porto Feliz, Guedes constatou que as elites locais dedicavam-se a outras atividades como comércio e que não deixaram de ser estimados socialmente. Desta forma, podiam não ter uma ideologia negativa do trabalho e, por isso, afirma a importância de se analisar cada realidade local e temporal e "ressaltar as nuances que as noções de trabalho tiveram na colônia/império e entre distintos segmentos sociais" (Guedes, 2008, p. 76). Desta maneira, o autor concentra sua análise nos indivíduos que não eram membros da elite, especificamente forros e descendentes, analisando o trabalho como uma das estratégias, uma das várias formas de mobilidade social.

Para abordar este grupo, Guedes se baseou em concepções de Stuart Schwartz (1988) e Hebe Mattos, se fundamentando nas questões de que a escravidão impunha referenciais de hierarquia distinguindo social e juridicamente escravos, livres, forros e descendentes de escravos e que a transposição de uma categoria jurídica a outra e o posterior afastamento de um antepassado escravo pressupõem passos na hierarquia social, para o qual a cor da pele podia estar relacionada. Assim, o autor analisa através de listas nominativas e mapas de habitantes, o trabalho relacionado a cor/condição social, e verifica como a ocupação diferenciou forros e descendentes de escravos e ambos entre si, corroborando com evidências de que o trabalho propiciava mobilidade social expressas na cor.

É válido ressaltar a preocupação do autor em relação ao cuidado que se deve ter durante a análise desses documentos, no que diz respeito à questão de quem atribuiu ou autoatribuiu a cor e de quem faz o registro, além da variação nas fontes, etc, pois nem sempre há consonância entre os termos utilizados por autoridades que elaboraram os mapas e os utilizados por recenseadores que fizeram as listas, mesmo que ambos se referissem a uma mesma cor/condição social. No geral, Guedes constatou, por exemplo, que a escravidão influenciou nas cores das pessoas em Porto Feliz e que o trabalho influenciou na oscilação da 
cor, o que era frequente. Em relação ao registro da cor, percebeu que o termo mulato pode ter tido um sentido pejorativo, e que ser caracterizado como branco marcava uma diferenciação fundamental em relação aos escravos e um distanciamento maior da escravidão em relação aos pardos. Enfim, na análise proposta pelo autor, a hierarquia e a posição social manifestas na cor eram fluidas e dependiam de circunstâncias sociais.

Vista pelo autor como o primeiro passo na hierarquia social, a alforria era onde os forros se diferenciavam dos escravos, por isso Guedes também procurou analisar como se dava essa passagem da escravidão para a liberdade, bem como alguns caminhos que conduziam à liberdade e seus momentos posteriores. $\mathrm{O}$ autor compreende a alforria como uma troca equitativa entre senhores e escravos, mas obviamente baseada na desigualdade, ou seja, uma relação de troca assentada na reciprocidade, sem esquecer que reciprocidade não é sinônimo de equivalência. Assim, nesta relação, do ponto de vista do escravo, o autor destaca a questão da submissão, que implica reconhecimento do poder senhorial, que juntamente com a obediência e os bons serviços prestados, podem ser vistos como estratégias de mobilidade social, uma vez que submissão não deve ser entendida apenas de forma unilateral, sendo necessário atentar para o interesse do submisso pela submissão, através das quais se podiam alcançar vantagens.

Outras formas de alforrias, de estratégias, destacadas pelo autor foram casos que, segundo ele, não eram frequentes, de ascensão social de cativas e/ou de seus filhos derivada de relações sexuais/afetivas com seus senhores, onde as ex-escravas e/ou seus filhos, além da liberdade, também herdaram alguns bens dos senhores. O matrimônio foi outro exemplo de forma de alforria, pois existiram casos de casamento de libertos(as) com escravas(os), onde a última foi alforriada. E uma vez inseridos na nova condição jurídico social, foi importante estabelecer relações sociais, as quais tinham sempre que ser reatualizadas para manutenção da nova posição, seja pelos forros ou seus descendentes.

É no último capítulo que percebemos a análise do autor por completo, pois através das trajetórias de algumas famílias ele comprova todas as suas hipóteses: a mobilidade social, seu tema central, relacionada conjuntamente ao trabalho, estabilidade familiar, mostrando a solidariedade intragrupal e a inserção em redes de sociabilidade, como as alianças com potentados locais, tudo isso associado à mudança no registro da cor da pele. Foram nessas trajetórias que o autor propôs aplicar o método da micro-história, e realizou o cruzamento de diversos tipos de fontes, analisando a mobilidade social dos egressos da escravidão, onde as trajetórias foram descritas passo a passo a fim de apreender tais estratégias. 
Encontrando pontos em comum nessas trajetórias, o autor mostrou que o trabalho podia ser percebido de forma positiva e ainda poderia propiciar margens de autonomia e ascensão social para forros e descendentes, não só em termos materiais, mas também no que diz respeito à reputação, às questões de reconhecimento e atuação social. Sobre a família e a inserção em redes de sociabilidade, os vínculos se percebem, por exemplo, nas relações de compadrio, e mesmo os que conseguiram ascender à condição de escravistas, não implicava o afastamento em relação aos seus iguais. Estes mantinham as relações horizontais, já que não havia porque fechar portas em um mundo instável, apadrinhavam filhos ou eram testemunhas de casamentos de escravos ou forros, mas para apadrinhar seus filhos preferiam pessoas com títulos como donas, tenentes, capitães, etc. Assim, Guedes nos fala da "transformação" de alguns pardos em brancos, como alguns pardos conseguiram se inserir no mundo senhorial, mostrando os fatores associados à mobilidade social também como um processo geracional.

O livro de Roberto Guedes, portanto, mostra como a mobilidade social contribuía para a manutenção de hierarquias sociais, não estando acessível a todos, mas tornando possível a forros e seus descendentes atuarem numa sociedade caracterizada pela desigualdade. $\mathrm{O}$ trabalho de Guedes contribui para estudos sobre a escravidão que se voltam para substituir a ideia de "vítima" pela de "agente social", ou seja, o escravo como um ser ativo na dinâmica da sociedade. Também é importante para estudos que buscam entender a participação social de libertos e seus descendentes, deixando de lado a visão de uma sociedade bipolarizada entre senhores e escravos, com aquele grupo incluído entre os vadios, os desclassificados sociais, com poucas chances de ascensão social; estudos que se voltam para a análise dos usos e significados sociais dos designativos de cor, bem como os que abordam a alforria, principalmente com enfoque para áreas rurais, o que pode servir também para estudos comparativos entre regiões urbanas e rurais.

Referências bibliográficas

MATTOS, Hebe. Das cores do silêncio: os significados da liberdade no sudeste escravista. Rio de Janeiro: Arquivo Nacional, 1995.

Escravidão e Cidadania no Brasil Monárquico. Rio de Janeiro: Zahar, 2000.

SCHWARTZ, Stuart. Segredos Internos: engenhos e escravos na sociedade colonial, 15501835. São Paulo: Companhia das Letras, 1988. 